\title{
CORRECTION
}

\section{Correction: Residential dust lead levels and the risk of childhood lead poisoning in United States children}

Joseph M. Braun, Kimberly Yolton, Nicholas Newman, David E. Jacobs, Mark Taylor and Bruce P. Lanphear

Pediatric Research (2021) 90:922; https://doi.org/10.1038/s41390-020-01229-0

Correction to: Pediatric Research https://doi.org/10.1038/s41390020-1091-3, published online 28 July 2020

Following publication of this article, the authors noticed that the units in Table 1 were incorrect. Dust lead loadings were measured in micrograms per square foot $\left(\mu \mathrm{g} / \mathrm{ft}^{2}\right)$, and not milligrams per square foot $\left(\mathrm{mg} / \mathrm{ft}^{2}\right)$.

This has now been corrected in both the PDF and HTML versions of this article. 